Cita bibliográfica: Oliveira Tavares, F. y Fraiz Brea, J. A. (2020). Análise confirmatória à preferência nos Hostels na cidade do Porto, em Portugal.Investigaciones Turísticas(19), pp.104-120. https://doi.org/10.14198/INTURI2020.19.05

\title{
Análise confirmatória à preferência nos Hostels na cidade do Porto, em Portugal
}

\author{
Análisis confirmatorio a preferir los albergues en la ciudad de Oporto en Portugal \\ Confirmatory analysis of the preference for hostels in the city of Oporto, Portugal
}

Fernando Oliveira Tavares (D), Instituto Superior de Ciências Empresariais e do Turismo, Portugal ftavares@iscet.pt

Jose Antonio Fraiz Brea (iD, Universidad de Vigo, España

jafraiz@uvigo.es

\section{RESUMO}

Este artigo tem como objetivo analisar e confirmar as caraterísticas determinantes na escolha de hostels na cidade do Porto, em Portugal. Foi efetuado um inquérito que foi respondido por 208 hóspedes deste tipo de equipamento hoteleiro. Os hostels estão integrados num segmento low cost, tratando-se por isso de um local de hospedagem barato, para hóspedes que não procuram o luxo, sendo por isso associados a turismo de jovens mochileiros. A análise confirmatória efetuada apresenta oito fatores que estão na base da sua escolha e são: a segurança geral do hostel, a limpeza do hostel, o mobiliário básico do hostel, os serviços de apoio aos hóspedes, o design e ambiente, as externalidades positivas de localização, o convívio e entretenimento dos hóspedes e a segurança física objetiva dos hostels. Trata-se de uma análise confirmatória, onde os trinta e oito itens agrupados em oito fatores, são um forte contributo para o estudo do tema, devendo merecer a atenção por parte dos gestores destas unidades hoteleiras, dos investidores e do público em geral.

Palavras Chave: Hostels; atributos dos hostels; amenidades dos hostels; hotelaria low cost.

\section{RESUMEN}

Este artículo tiene como objetivo analizar y confirmar las características que determinan la hora de elegir los albergues en Oporto, Portugal. Se realizó una encuesta a 208 huéspedes de este tipo de alojamiento. Los hostels están integrados en un segmento de bajo coste, considerándose alojamientos económicos, para huéspedes que no buscan lujo, asociándose al turismo de jóvenes mochileros. El análisis confirmatorio efectuado presenta ocho factores que forman la base de su elección y son: la seguridad general del hostel, la limpieza del hostel, el 
mobiliario básico del hostel, los servicios de apoyo a los huéspedes, el diseño y el ambiente, las externalidades positivas de la ubicación, la convivencia y el entretenimiento de los huéspedes y la seguridad física objetiva de los hostels. Se trata de un análisis confirmatorio, donde los treinta y ocho elementos agrupados en ocho factores contribuyen significativamente al estudio de la temática, debiendo captar la atención de los gestores de estas unidades hoteleras, de los inversores y del público en general.

Palabras clave: Hostels; atributos de los hostels; comodidades de los hostels; hotelería low cost.

\section{ABSTRACT}

The objective of this paper is to analyse and to confirm the characteristics that determine the choice of hostels in the city of Oporto, Portugal. A survey was carried out among 208 guests of this kind of accommodation. Hostels form part of the low-cost segment. They are considered to be affordable lodging places for guests who do not seek luxury and therefore are associated with backpacking tourism. The confirmatory analysis identifies eight factors that form the basis of their choice, namely: the security of the hostel in general, its cleanliness, the hostel's basic furniture, its support services to guests, the design and atmosphere, the positive externalities of location, conviviality and guest entertainment and the physical and objective safety of the hostel. It is a confirmatory analysis, whereby thirty-eight items grouped into eight factors make a considerable contribution to the study of the topic. Therefore, it should be of interest to managers of these types of accommodation, investors and the general public.

Keywords: Hostels; hostels' attributes; hostels' amenities; low-cost hotels.

\section{INTRODUÇÃO}

Os hostels são procurados por jovens turistas internacionais, independentes, que usufruem baixos rendimentos e orçamentos para viajar e fazer férias. Os hostels representam um setor low cost em crescimento no turismo em Portugal (Moreira, Tavares, Pereira, 2014). O hostel é mais informal e orientado para a aventura quando comparado com o hotel tradicional, sendo também por isso, mais do agrado dos jovens turistas, que tem mais flexibilidade de viagem e procuram a confraternização e a sociabilização com pessoas da sua faixa etária.

Os quartos nos hostels podem dispor de várias camas ou beliches, num quarto partiIhado, com casa de banho partilhada, lavandaria e cozinha. A hospitalidade é a essência dos hostels e resulta da relação de proximidade entre acolhedor e acolhido. Existem fatores com impacto positivo na atratividade e nos preços dos hostels: a atmosfera, a limpeza, as comodidades das instalações e a localização são disso exemplos.

Este trabalho tem como objetivo, analisar e confirmar as caraterísticas determinantes na escolha de hostels na cidade do Porto, em Portugal. O presente artigo encontra-se estruturado em cinco pontos. Após esta introdução, é apresentada uma revisão da literatura sobre o tema. No terceiro ponto é apresentada a metodologia de investigação, utilizada na análise fatorial confirmatória. No quarto ponto, são analisados e interpretados os resultados 
do inquérito e da análise fatorial confirmatória. No último ponto, faz-se uma reflexão / conclusão do trabalho elaborado.

\section{REVISÃO DA LITERATURA}

A revisão da literatura apresenta os estudos recentes sobre os hostels referindo quais as variáveis e fatores valorizados pelos hóspedes neste tipo de indústria. Esta revisão da literatura, está dividida em três vertentes: caraterísticas deste tipo de indústria, conhecer a literatura internacional sobre o tema e perceber quais as variáveis e fatores importantes para os hóspedes.

\section{a) Caraterísticas deste tipo de indústria}

Uma observação óbvia, é que é uma indústria low cost, destinada aos hóspedes que procuram locais baratos e que por isso abdicam do luxo. É um tipo de alojamento cujo hóspede é maioritariamente jovem, no geral com formação superior, que procuram informação pela internet (www.hostelworld.com), sendo sensíveis à existência de transportes públicos e a locais de diversão noturna. O rececionista funciona como um dos pilares do negócio, pois o seu papel é fazer com que o hóspede se sinta à vontade e assim primar pela hospitalidade, existência de uma boa atmosfera e informalidade.

Algumas dessas caraterísticas são apresentadas na Tabela 1.

Tabela 1. Caraterísticas dos hostels

\begin{tabular}{|c|c|}
\hline Autor (ano) & Caraterísticas dos hostels \\
\hline Valls (2016) & $\begin{array}{l}\text { Hostels são consequência da impulsão do conceito low-cost nas } \\
\text { operadoras aéreas. }\end{array}$ \\
\hline $\begin{array}{l}\text { Dublin (2003) } \\
\text { Rashid-Radha (2015) } \\
\text { Abrantes (2014) } \\
\text { Tavares, Pacheco, Borges } \\
\text { (2016) }\end{array}$ & Local de hospedagem barato, para viajantes que não procuram o luxo. \\
\hline $\begin{array}{l}\text { Timothy e Teye (2009) } \\
\text { Volante (2011) }\end{array}$ & Associado a turismo de jovens mochileiros. \\
\hline Abrantes (2014) & Quartos com camas ou beliches vendidos individualmente. \\
\hline Volante (2011) & Localização em centro de cidades e em zonas históricas. \\
\hline $\begin{array}{l}\text { Brochado e Gameiro } \\
\text { (2013); Tavares e Fraiz Brea } \\
\text { (2017). }\end{array}$ & Hostels são locais informais, orientados para a aventura. \\
\hline $\begin{array}{l}\text { Tavares, Pereira, Moreira } \\
\text { (2012) }\end{array}$ & $\begin{array}{l}\text { Existem externalidades intrínsecas ao projeto e a variações } \\
\text { de layout que devem ser levadas com muito rigor, quer por } \\
\text { quem planeia, quer por quem investe, pois o design e a localização } \\
\text { tem grande impacto nos hostels. }\end{array}$ \\
\hline Silva (2014) & Os hostels primam pela hospitalidade. \\
\hline
\end{tabular}




\begin{tabular}{|l|l|}
\hline Bahls e Pereira (2017) & $\begin{array}{l}\text { As áreas essenciais num hostel são: área social externa, casa de } \\
\text { banho para cada dormitório, cozinha comum, dormitório, arrumos, } \\
\text { lavandaria e sala de estar. }\end{array}$ \\
\hline $\begin{array}{l}\text { Martins, Rachão e Costa } \\
\text { (2018) }\end{array}$ & $\begin{array}{l}\text { Os hóspedes valorizam aspetos intangíveis como o «tempo» a } \\
\text { «amizade» que permite uma satisfação na estadia e promove as } \\
\text { análises positivas. Elementos tangíveis a referenciar no hostel são: a } \\
\text { localização e as atividades culturais e sociais organizadas pela equipa. }\end{array}$ \\
\hline Kim \& Perdue (2013 & $\begin{array}{l}\text { Os clientes a escolherem um hotel não consideram apenas os } \\
\text { atributos cognitivos (ex: preço, serviço, qualidade, marca) mas } \\
\text { também afetivos (ex: sensação de conforto e divertimento) e sensorial } \\
\text { (ex: qualidade do quarto, atmosfera geral). }\end{array}$ \\
\hline
\end{tabular}

Fonte: Elaboração própria

Ainda como caraterística, os hostels apresentam não só quartos com camas para uma ou duas pessoas, mas também quartos com beliches para um maior número de pessoas, normalmente localizadas nos centros das cidades ou em zonas históricas.

\section{b) Conhecer a literatura internacional sobre o tema}

São vários os estudos internacionais apresentados sobre o tema. Desde Portugal, ao Brasil, Inglaterra, Polónia entre outros. No geral os hostels apresentam as caraterísticas apresentadas no ponto anterior, no entanto, assim não acontece em alguns países.

$\mathrm{Na}$ Europa, em alguns países os hostels tiveram a sua origem em albergues para pessoas carenciadas (Fitzpatrick, Wygnanska, 2007). Estes albergues eram dormitórios que entretanto foram sofrendo obras de requalificação, mas que por vezes continuam a ser locais impessoais, onde não abunda a hospitalidade. O staff é normalmente composto por um gerente e pelo ajudante, com dois quartos amplos, equipados com dez a quinze beliches e casas de banho comuns, geralmente localizados em periferias de cidades e vilas e muitas vezes mais próximos de zonas industriais do que de zonas residenciais.

Cró et al (2018) investigaram e avaliaram o impacto da segurança dos hostels sobre a disposição dos clientes na hora de pagar. Os autores destacam a importância da segurança na determinação dos preços dos quartos dos hostels. Concluíram que os clientes estão dispostos a pagar um prémio de preço nos países menos pacíficos do mundo, por um quarto num hostel com níveis mais elevados de segurança. No caso de mulheres e idosos o prémio que eles estão dispostos a pagar é ainda maior. Bahls e Pereira (2017) concluíram que no Brasil alguns empreendimentos existentes não se adequam às caraterísticas essenciais internacionais deste meio de hospedagem, devido à sua formação socio espacial e conceitos de hospitalidade diferenciados.

Mikulić et al (2016) investigaram sobre se as caraterísticas sociodemográficas e comportamentais dos turistas hospedados num hostel em Zagreb, na Croácia. No seu estudo observaram que a maioria dos hóspedes são pessoas jovens, onde apenas 10,6\% têm mais de 30 anos. Também se pode observar que 52,4\% são estudantes e 39,3\% estão empregados. Os autores concluem que os donos dos hostels e as organizações institucionais devem 
concentrar-se no sentido de melhorar os conteúdos dos destinos turísticos e mais políticas de produto, para elevar a atração da imagem de destino. Referem que os gestores devem criar perceções positivas do lugar.

Hory et al (2017) estudaram as formas de construção dos hostels. Observaram que nos hostels os proprietários são motivados por ocuparem edifícios já existentes em vez de construções feitas de raiz. Procuram a informalidade dos espaços e das mobílias para evitar alterações constantes. Cró e Martins (2018) estudaram os potenciais fatores que contribuem para a escolha da localização de hotéis e de hostels na zona de Lisboa em Portugal. Segundo os autores os resultados mostram que em geral o acesso a transportes públicos, restaurantes e atrações culturais não são fatores cruciais na localização de hotéis e hostels. Os resultados do estudo revelam que os hotéis de classe superior localizam-se na zona da Expo, que a localização dos hostels de grau superior é nas áreas urbanas recentemente reabilitadas, que se caraterizam por serem lugares mais seguros, mais longe da vida noturna e perto de zonas comerciais, afastando-se do centro da cidade. No que diz respeito aos hotéis e hostels de menor qualidade, os resultados não revelam diferenças no padrão de localização de ambos. Os autores entendem que os hotéis e hostels de baixa qualidade procuram ativamente os benefícios dos efeitos da aglomeração.

Veríssimo e Costa (2018) identificaram as melhores práticas e tendências de hostels e avaliaram e discutiram como os hostels estão a acompanhar a procura atual criada pelo mercado dos millennials. Os resultados do seu estudo indicam que enquanto permanecem nos albergues os millennials querem: conhecer pessoas, participar em atividades e eventos, ter experiências locais, de se sentirem confortáveis na casa, pagarem um valor justo e desfrutarem dessa conveniência. Os hostels (em troca) desempenham um papel importante na indústria da hospitalidade ao agradar aos millennials, oferecendo: localização central e um conjunto de atividades e de tratamento personalizado.

Wahlberg, Ramalho e Brochado (2017) investigaram se a retenção de funcionários que se preocupam com o hostel (que estão há mais anos no hostel), tem a ver com o facto de possuírem uma qualidade de vida melhor no trabalho e se o seu envolvimento no trabalho medeia esse relacionamento. Os resultados revelam que a qualidade de vida no trabalho tem um forte impacto negativo no comportamento de saída dos funcionários e um efeito positivo na sua lealdade. $O$ envolvimento no trabalho foi tido como mediador da relação entre a qualidade de vida profissional e a voz da negligência, bem como da intenção de saída.

\section{c) Perceber quais as variáveis e fatores importantes para os hóspedes}

Algumas das variáveis e fatores importantes para os hóspedes são apresentados na Tabela 2. Observa-se que as variáveis de decisão na escolha dos hóspedes estão relacionadas com o facto de se tratar de um alojamento barato, de permitir maior tempo de viagem e organizar as viagens de uma forma mais flexível e ainda permitir atividades mais informais nas férias. 
Aspetos preponderantes na escolha são também a limpeza dos quartos, a atmosfera que se respira no hostel, a qualidade e comodidade dos serviços, a segurança e a sociabilidade da equipa de gestão.

Sendo o preço um fator de decisão para quem utiliza os hostels, é uma caraterística difícil de avaliar no mercado de alojamento, pois para além da dormida pode incluir acesso a outros serviços e facilidades. Uma noite pode ser entendida como um pacote com diferentes itens e que podem ir desde a localização à atmosfera que se vive no hostel. Existem no entanto fatores que podem ter um impacto negativo nos preços, como sejam a atitude pouco delicada do staff ou a falta de limpeza.

Tabela 2. Fatores determinantes na procura de hostels

\begin{tabular}{|l|l|}
\hline \multicolumn{1}{|c|}{ Autores } & \multicolumn{1}{c|}{ Fatores determinantes } \\
\hline Wilson, Ateljevic, Hannam, Ate- & - Alojamento barato; \\
lievic, (2008) & - Conhecer outros viajantes; \\
& - Viagens organizadas de forma independente e flexível; \\
& - Permitem mais tempo de viagem; \\
\hline - Permitem atividades mais informais nas férias. \\
\hline Brochado, Gameiro (2013) & - Limpeza dos quartos; \\
Musa, Martin (2006) & - Preço dos quartos; \\
Bahls (2015) & - Localização; \\
Timothy e Teye (2009) & - Qualidade dos serviços; \\
& - Segurança; \\
& - Sociabilidade da equipa de gestão do hostel; \\
& - Atmosfera; \\
& - Serviços de internet. \\
\hline Santos (2016) & - Atmosfera; \\
& - Limpeza; \\
& - Comodidades das instalações; \\
& - Localização; \\
& - Segurança; \\
& - Quartos individuais. \\
\hline
\end{tabular}

Fonte: Elaboração própria

Naturalmente que a rentabilidade de um hostel depende do próprio hostel, dos fatores que lhe são intrínsecos, mas também depende do destino turístico em que opera, da taxa de ocupação e desse destino turístico. 


\section{METODOLOGIA}

Para estudar as características procuradas nos hostels que foram salientadas na revisão da literatura, foi elaborado um inquérito. $O$ inquérito foi colocado em hostels, nos meses de julho, agosto e setembro de 2016, a fim de serem preenchidos por indivíduos que estivessem hospedados nos hostels da cidade do Porto, em Portugal. Foram obtidas 208 respostas.

Recorreu-se ao Software SPSS 21 para tratamento do inquérito. No presente estudo recorremos à Análise Fatorial Confirmatória para avaliar o modelo de medida (Marôco, 2010). O modelo de medida, que estabelece as relações que ligam os construtos aos indicadores e os construtos entre si, foi estimado através do software já mencionado e utilizando o método de estimação da Máxima Verosimilhança, método robusto mesmo quando ocorre a violação do pressuposto da normalidade dos dados (HAIR JR., BLACK, BABIN, \& ANDERSON, 2010).

Para a avaliação da adequação do modelo, recorremos a um conjunto de índices de ajustamento, sendo escolhidos os mais referidos na literatura (MARÔCO, 2010), nomeadamente o teste de Qui-Quadrado relativo $\left(\chi^{2} / g I\right)$, o Goodness of Fit Index (GFI), o Comparative Fit Index (CFI), o Tucker-Lewis Index (TLI) e o Root Mean Square Error of Approximation (RMSEA). Relativamente aos pontos de corte destes índices, consideramos um bom ajustamento do modelo quando: (1) o valor do $\chi^{2} / g$ é inferior a 2 ou 3; (2) os valores do CFI, do TLI e do GFI são maiores do que 0.90 (para o GFI são considerados aceitáveis valores superiores a 0.80, de acordo com Hu \& Bentler (1999) e Brown (2006)rather than mathematics or formulas, this accessible book has established itself as the go-to resource on confirmatory factor analysis (CFA; (3) o valor do RMSEA é inferior 0.10 (MARÔCO, 2010).

Seguiu-se a avaliação da validade convergente (se o construto em estudo se correlaciona positiva e significativamente com outros construtos teoricamente paralelos e os itens que o constituem apresentam correlações positivas e elevadas) e da validade discriminante (se os itens que refletem um construto não estão correlacionados com outros construtos) (MARÔCO, 2010).

No presente estudo, para avaliar a validade convergente seguimos a recomendação de Fornell \& Larcker (1981), que propõem a sua medição através da Variância Extraída Média (VEM), das cargas fatoriais e da Fiabilidade Composta (FC). De acordo com Hair Jr., Black, Babin, \& Anderson (2010), a carga fatorial deve ser superior ou igual a 0.50, um valor aceitável para a FC é no mínimo de 0.70 e para a VEM de 0.50 .

$$
\begin{aligned}
& \widehat{F C_{j}}=\frac{\left(\sum_{i=1}^{k} \lambda_{i j}\right)^{2}}{\left(\sum_{i=1}^{k} \lambda_{i j}\right)^{2}+\sum_{i=1}^{k} \varepsilon i j} \\
& \widehat{V E M}=\frac{\sum_{i=1}^{k} \lambda_{i j}^{2}}{\sum_{i=1}^{k} \lambda_{i j}^{2}+\sum_{i=1}^{k} \varepsilon i j}
\end{aligned}
$$


Onde:

$$
\begin{aligned}
& \sum_{i=1}^{k} \lambda_{i j}^{2}=\text { representa os coeficientes padronizados; } \\
& \sum_{i=1}^{k} \varepsilon i j=\text { representa os erros de medida. }
\end{aligned}
$$

A validade discriminante foi avaliada pelo método preconizado por Fornell \& Larcker (1981), que consiste na comparação entre a Variância Extraída Média (VEM) do construto com o quadrado dos coeficientes de correlação com os restantes construtos, sendo que a VEM deve apresentar valores superiores.

\section{ANÁLISE DOS FATORES DE ESCOLHA DE HOSTELS}

\subsection{Análise descritiva dos resultados dos hostels}

A amostra em estudo é constituída por 208 indivíduos com idades entre os 17 e os 64 anos e uma idade média aproximada de 27 anos $(\bar{x}=27,29)$. Em relação ao género verifica-se que $39,9 \%$ são do sexo masculino e $60,1 \%$ são do sexo feminino. Quanto à religião dos hóspedes, verifica-se que o maior destaque vai para o Cristianismo com 79,8\%, seguido do Islamismo com 1,4\%, a religião Budista com $0,5 \%$ e sem religião ou outras religiões com $18,3 \%$. Quanto ao estado civil, verifica-se o maior destaque para os solteiros com 76,9\%, seguindo-se os casados com $14,9 \%, 4,8 \%$ para os que vivem juntos, $2,9 \%$ são separados ou divorciados e $0,5 \%$ são viúvos. No que se refere à dimensão do agregado familiar, o mais frequente são famílias de quatro indivíduos por agregado familiar $(35,1 \%)$, seguido de famílias de três indivíduos (25,5\%), e de famílias de dois indivíduos (15,0\%) e posteriormente de um só indivíduo (12,0\%). $\mathrm{Na}$ amostra os hóspedes com família de cinco indivíduos representam 9,1\% e famílias de seis indivíduos representam 1,9\%, apresentando a amostra um valor residual para uma família de nove pessoas $(0,5 \%)$.

$\mathrm{Na}$ amostra cerca de $50 \%$ dos hóspedes dos hostels apresentam um rendimento familiar anual inferior a 20.000,00€. Dos 208 inquiridos, 35,1\% fazem viagens uma vez por ano, $27,4 \%$ duas vezes por ano e $37,5 \%$ três ou mais vezes por ano. Dos indivíduos que responderam ao inquérito, $54,3 \%$ ficou em quarto privado e $45,7 \%$ em dormitório. No que respeita ao nível de escolaridade $0,5 \%$ apresenta como nível de escolaridade o 60 ano, 35,1\% dos indivíduos tem o 12 ano como nível de escolaridade, $42,3 \%$ dos indivíduos tem como nível de formação a licenciatura, 18,8\% apresenta o nível de formação de mestrado e 3,4\% dos indivíduos tem como nível de escolaridade o doutoramento.

Quanto à duração da estadia no hostel, 22,1\% dos indivíduos da amostra pernoita uma noite, $24,5 \%$ dos indivíduos duas noites, $24,0 \%$ dos indivíduos três noites, $13,0 \%$ quatro noites, $9,6 \%$ dos indivíduos fica entre cinco a sete noites e $6,7 \%$ dos indivíduos mais de sete noites. 
No que se refere à experiência de estadia anterior em hostels, 30,3\% nunca se tinha hospedado em hostels, $27,9 \%$ dos indivíduos tinha já pernoitado entre uma a três noites, $13,9 \%$ entre quatro a seis noites, $6,3 \%$ entre dez a catorze noites e $16,8 \%$ mais de 15 noites.

Dos 208 inquiridos, $42,8 \%$ dos indivíduos ficaram no hostel com amigos, seguindo-se em termos percentuais $17,8 \%$ que ficaram com companheiro e $16,8 \%$ dos indivíduos que ficaram sozinhos. Com a família ficaram $16,3 \%$ dos indivíduos e $6,3 \%$ dos indivíduos ficaram integrados num grupo.

Quanto ao objetivo da estadia no hostel, $53,8 \%$ dos indivíduos da amostra estavam em turismo, 19,2\% dos indivíduos tinham como objetivo conhecer uma nova cidade, $8,2 \%$ tinham como objetivo relaxar e 6,3\% dos indivíduos tinham como objetivo ver eventos culturais. Outras respostas a esta questão são: $2,9 \%$ tem como objetivo trabalhar, $2,4 \%$ estudar, $2,4 \%$ para ver eventos desportivos, $1,9 \%$ visitar amigos, $1,0 \%$ conhecer pessoas, $0,5 \%$ fazer amigos e 1,4\% outros objetivos não especificados anteriormente.

Quanto à forma de procura do hostel, 63,9\% dos indivíduos da amostra utiliza o site sobre hostels (booking), $21,6 \%$ dos indivíduos utiliza o site do hostel, 9,6\% dos indivíduos recorrem à família e a amigos, $1,9 \%$ recorre a livros e guias, $0,5 \%$ recorre a jornais e $2,4 \%$, a outras formas não especificadas anteriormente. No que se refere ao meio de transporte utilizado na viagem, $47,1 \%$ dos indivíduos utiliza o carro, $41,8 \%$ utiliza o avião, 9,6\% dos indivíduos utiliza o comboio, $1,0 \%$ a moto e $0,5 \%$ o barco.

Da análise ao resultado do inquérito sobre hostels, podemos verificar que a média de idades dos hóspedes é de 27 anos, sendo por isso uma amostra de uma população jovem, maioritariamente solteira (76,9\%), com um rendimento familiar não muito elevado, que preferem ficar em quartos privados a dormitórios, com estadia de duas a três noites. Normalmente fazem viagens acompanhados de amigos, em turismo, com o objetivo de conhecer uma nova cidade. Recorrem ao site de hotels (booking) e utilizam o carro e o avião para viajarem. Os hostels são os maiores concorrentes do hotel convencional. Os hóspedes preferem que os hostels possuam computadores com acesso à internet, com cozinha disponível e escolhem este alojamento ao hotel tradicional pelo facto de ficar mais barato e permitirem organizar as viagens de forma mais flexível. Há no entanto alguns aspetos que não são valorizados pelos hóspedes, como a existência de micro-ondas, o multibanco ou a lavandaria com máquinas de secar e lavar.

Das respostas ao inquérito sobre o conforto, entretenimento no espaço, segurança e apoio turístico, os hóspedes dão grande importância à limpeza do local, à boa aparência das áreas comuns e ao facto de possuir uma área envolvente agradável. Outro aspeto que valorizam bastante é a segurança, não só dentro do hostel, mas também da área envolvente. Os hóspedes do hostel necessitam de informação sobre as atrações locais. Sobre os itens relacionados com a localização do hostel, os hóspedes preferem zonas seguras, próximas de transportes públicos e zonas históricas. O hostel deve ter um ambiente acolhedor, calmo e tranquilo, com instalações funcionais e que possua equipamentos modernos. Aspetos menos valorizados no grupo de questões sobre o conforto, entretenimento, segurança e apoio turístico, são itens como a existência de sala de leitura no hostel, os equipamentos de entretenimento, a existência de 
parque de estacionamento e de um circuito fechado de tv, assim como não valorizam também o aluguer de material de apoio (bicicleta e outros), a venda de atividades turísticas, a consulta gratuita de literatura de viagem e o aluguer de carro. No que se refere à localização não são valorizadas as localizações junto a universidades ou o facto de ter proximidade a áreas desportivas, sendo uma situação de indiferença o facto de possuir ou não habitação na vizinhança.

\subsection{Análise Fatorial Confirmatória às preferências nas escolhas relacionadas com o hostel}

O modelo de medida inicialmente avaliado apresentou-se insatisfatório, dado que alguns índices de ajustamento revelaram um ajustamento insatisfatório: $\chi^{2} / g \mathrm{gl}=2,189 ; \mathrm{GFI}=$ 0,742; $\mathrm{CFI}=0,836, \mathrm{TLI}=0,820$; e ainda o $\mathrm{RMSEA}=0,076$.

Todos os itens apresentam cargas fatoriais elevadas, superiores a 0,50 (Marôco, 2010). Recorrendo aos índices de modificação, foi possível constatar valores elevados para a covariância entre os erros associados às variáveis DA1 e DA2, DA3 e DA4, SGH6 e SFOH3, assim como entre o erro associado à variável SGH6 e o fator SFOH. Tendo em conta estes resultados e com o objetivo de melhorar o modelo este foi reespecificado, excluindo o item SGH6 e correlacionando os erros dos pares de variáveis referidos que se encontravam no mesmo fator.

Após a reespecificação do modelo (Figura 1), verificaram-se melhorias em todos os índices de ajustamento $\left(\chi^{2} / g I=1,918 ; \mathrm{GFI}=0,774 ; \mathrm{CFI}=0,872 ; \mathrm{TLI}=0,859\right.$ e RMSEA =0,067). Apesar de os índices CFI, GFI e TLI ainda se encontrarem ligeiramente abaixo dos pontos de corte recomendados, estes valores devem ser relativizados tendo em conta que estes podem ser afetados pela dimensão da amostra (Marôco, 2010). Neste novo modelo verificamos que os itens mantêm cargas fatoriais superiores a 0,50.

O primeiro fator apresenta os itens relacionados com a segurança geral do hostel. $\mathrm{O}$ segundo fator refere-se à limpeza do hostel e o terceiro fator ao mobiliário básico do hostel. 0 quarto fator são os serviços de apoio aos hóspedes, do qual fazem parte itens como o aluguer de material e o serviço de transporte. O quinto fator é o design e ambiente do hostel. Os hóspedes valorizam a decoração e design interior e exterior, os equipamentos e instalações modernas, naturalmente tudo inserido num ambiente acolhedor e confortável. O sexto fator são externalidades positivas de localização, de onde se destaca a proximidade a água seja rio ou mar, a proximidade a jardins e parques públicos cuidados e outras belezas exteriores circundantes.

O sétimo fator é o convívio e entretenimento entre os hóspedes. Tratando-se de hóspedes de uma faixa etária jovem, procuram ambientes que permitem conhecer outros jovens viajantes, com salas de convívio e lhes permitam experiências únicas de viagem. $\mathrm{O}$ oitavo fator é a segurança física objetiva do hostel, apresentando itens relacionados com a segurança geral do hostel mas também da possibilidade de ter um cofre individual para guardar bens e documentos pessoais. 
Figura 1. Estrutura fatorial confirmatória das preferências dos hóspedes dos Hostels

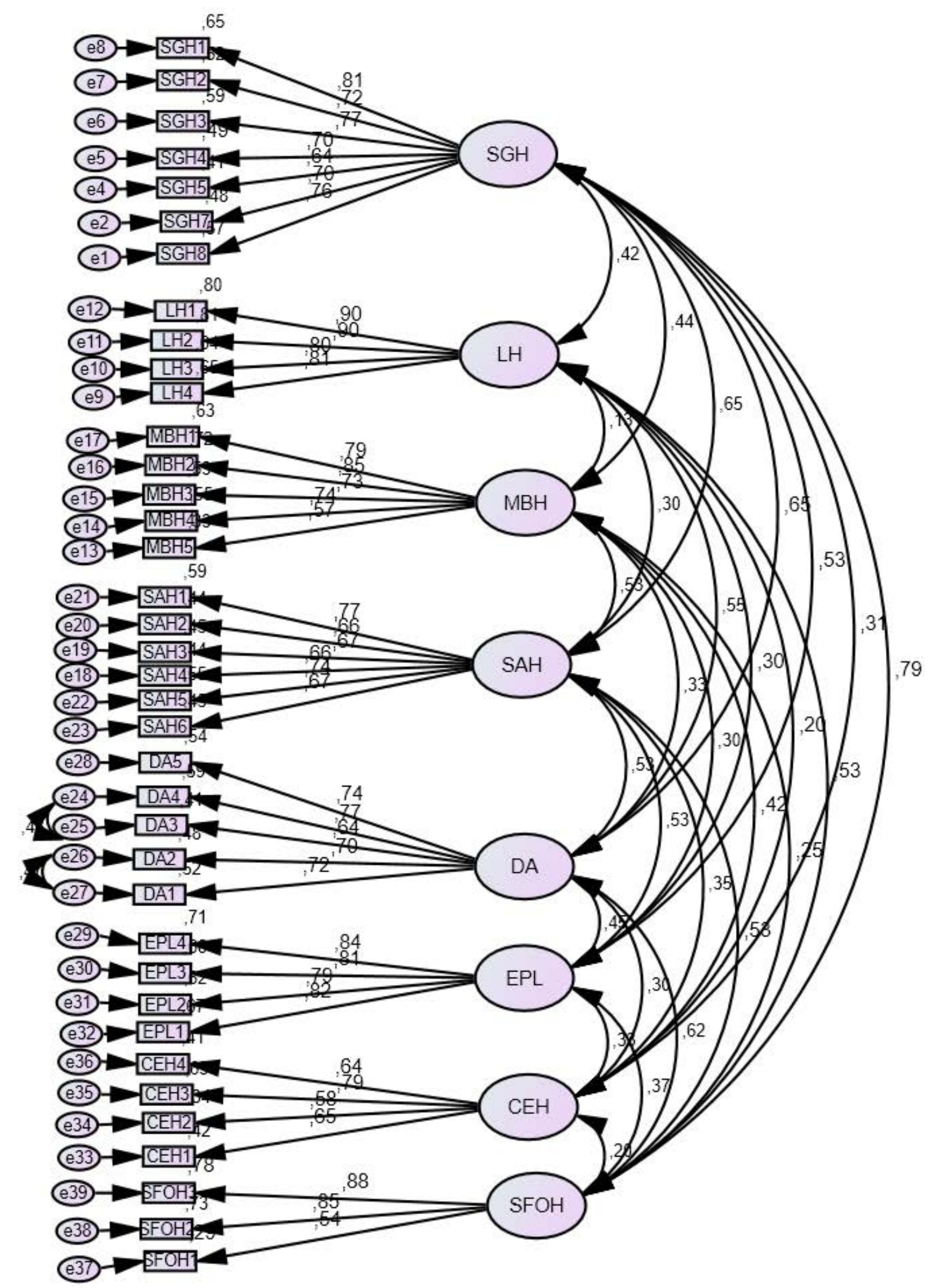


Quadro 1. AFC resultante das preferências das escolhas dos utilizadores dos hostels

\begin{tabular}{|c|c|c|}
\hline Variáveis associadas & Código & Fator \\
\hline - Portas Janelas com Segurança & $-\mathrm{SGH} 1$ & \multirow{7}{*}{$\begin{array}{c}\text { Segurança Geral } \\
\text { do Hostel }\end{array}$} \\
\hline - Existência Funcionário Portaria & $-\mathrm{SGH} 2$ & \\
\hline - Vigilância Polícia Redondezas & $-\mathrm{SGH} 3$ & \\
\hline - Circuito Fechado TV & $-\mathrm{SGH} 4$ & \\
\hline - Necessário Cartão Acesso Quartos & $-\mathrm{SGH} 5$ & \\
\hline - Alarme Incêndio & $-\mathrm{SGH} 7$ & \\
\hline - Luz Noturna & $-\mathrm{SGH} 8$ & \\
\hline - Limpeza da Zona dos Banhos & $-\mathrm{LH} 1$ & \multirow{4}{*}{$\begin{array}{l}\text { Limpeza } \\
\text { do Hostel }\end{array}$} \\
\hline - Limpeza Quartos Dormitórios & $-\mathrm{LH} 2$ & \\
\hline - Limpeza da Cozinha & $-\mathrm{LH} 3$ & \\
\hline - Limpeza Áreas Comuns & $-\mathrm{LH} 4$ & \\
\hline - Fogão com Forno & $-\mathrm{MBH} 1$ & \multirow{5}{*}{$\begin{array}{c}\text { Mobiliário Básico } \\
\text { do Hostel }\end{array}$} \\
\hline - Multibanco & $-\mathrm{MBH} 2$ & \\
\hline - Micro Ondas & $-\mathrm{MBH} 3$ & \\
\hline - Internet (wi-fi) & $-\mathrm{MBH} 4$ & \\
\hline - Restaurante & $-\mathrm{MBH} 5$ & \\
\hline - Aluguer Material Apoio & - SAH1 & \multirow{6}{*}{$\begin{array}{c}\text { Serviços de } \\
\text { Apoio aos Hóspedes }\end{array}$} \\
\hline - Serviço de Transporte & $-\mathrm{SAH} 2$ & \\
\hline - Venda de Atividades Turísticas & $-\mathrm{SAH} 3$ & \\
\hline - Informação sobre Atrações Locais & $-\mathrm{SAH} 4$ & \\
\hline - Ligação Central Táxis & -SAH5 & \\
\hline - Literatura de Viagem & -SAH6 & \\
\hline - Design e Decoração Interior & $-\mathrm{DA} 1$ & \multirow{5}{*}{$\begin{array}{l}\text { Design e } \\
\text { Ambiente }\end{array}$} \\
\hline - Design Exterior Atrativo & $-\mathrm{DA} 2$ & \\
\hline - Instalações Equipamentos Modernos & $-\mathrm{DA} 3$ & \\
\hline - Instalações Modernas & $-\mathrm{DA} 4$ & \\
\hline -Ambiente Acolhedor e Confortável & - DA5 & \\
\hline - Proximidade a Rio & $-E P L 1$ & \multirow{4}{*}{$\begin{array}{c}\text { Externalidades } \\
\text { Positivas de Localização }\end{array}$} \\
\hline - Proximidade a Jardins e Parques & $-E P L 2$ & \\
\hline - Proximidade Belezas Exteriores Circundantes & $-E P L 3$ & \\
\hline - Proximidade a Praia & $-E P L 4$ & \\
\hline - Conhecer Novos Viajantes & $-\mathrm{CEH} 1$ & \multirow{4}{*}{$\begin{array}{c}\text { Convívio e } \\
\text { Entretenimento } \\
\text { dos Hóspedes }\end{array}$} \\
\hline - Permite Experiência Única & $-\mathrm{CEH} 2$ & \\
\hline - Ambiente Permite Conhecer Novas Pessoas & $-\mathrm{CEH} 3$ & \\
\hline -Sala Comum Convívio & $-\mathrm{CEH} 4$ & \\
\hline - Cofre Individual & -SFOH1 & \multirow{3}{*}{$\begin{array}{l}\text { Segurança Física } \\
\text { Objetiva do Hostel }\end{array}$} \\
\hline - Segurança do Hostel & $-\mathrm{SFOH} 2$ & \\
\hline - Segurança Área Localização Hostel & $-\mathrm{SFOH3}$ & \\
\hline
\end{tabular}

Fonte: Elaboração própria 


\subsection{Validade convergente e validade discriminante}

Conforme podemos observar na Tabela 3 os valores da FC são superiores a 0,70. Os valores obtidos para a VEM de cada construto (na diagonal da Tabela 3) são superiores a 0,50 à exceção dos construtos CEH e SAH. No entanto, Fornell \& Larcker (1981) acrescentam que um limite inferior de 0.40 para os valores da VEM é aceitável desde que a FC seja superior a 0.60 . Conforme podemos observar na Tabela 3 os valores da FC são superiores a 0,70 e os valores obtidos para a VEM (na diagonal da Tabela 3) são superiores a 0,40, verificando-se a validade convergente da escala.

A validade discriminante foi testada pelo critério de Fornell \& Larcker (1981), que consiste na comparação entre a Variância Extraída Média (VEM) do construto com o quadrado dos coeficientes de correlação com os restantes construtos (restantes entradas da Tabela 3), sendo que a VEM deve apresentar valores superiores. De acordo com os dados expostos na Tabela 10 foi detetado apenas um caso de ausência de validade discriminante, nomeadamente entre o par de construtos SGH e SFOH.

Tabela 3. Fiabilidade Composta (FC), Variância Extraída Média (VEM) e quadrado da correlação entre construtos

\begin{tabular}{llllllllll}
\hline & FC & CEH & SGH & LH & MBH & SAH & DA & EPL & SFOH \\
\hline CEH & 0,765 & $\mathbf{0 , 4 5 2}$ & & & & & & & \\
SGH & 0,888 & 0,098 & $\mathbf{0 , 5 3 1}$ & & & & & & \\
LH & 0,914 & 0,040 & 0,173 & $\mathbf{0 , 7 2 8}$ & & & & & \\
MBH & 0,859 & 0,176 & 0,196 & 0,017 & $\mathbf{0 , 5 5 3}$ & & & & \\
SAH & 0,849 & 0,126 & 0,417 & 0,089 & 0,282 & $\mathbf{0 , 4 8 5}$ & & & \\
DA & 0,837 & 0,088 & 0,429 & 0,304 & 0,108 & 0,283 & $\mathbf{0 , 5 0 8}$ & & \\
EPL & 0,889 & 0,106 & 0,283 & 0,089 & 0,088 & 0,286 & 0,203 & $\mathbf{0 , 6 6 6}$ & \\
SFOH & 0,813 & 0,039 & 0,623 & 0,280 & 0,065 & 0,280 & 0,389 & 0,134 & $\mathbf{0 , 6 0 2}$ \\
\hline
\end{tabular}

Fonte: Elaboração própria

Para os pares de construtos onde se verificou ausência de validade discriminante pelo método anterior, foi realizado um novo teste à validade discriminante, seguindo o procedimento recomendado por Bagozzi, Yi, \& Phillips (1991). Esse procedimento consiste na comparação entre dois modelos testados para o par de construtos; um modelo onde a covariância é forçada em 1 e outro modelo onde a covariância é deixada livre. Calcula-se a diferença entre as estatísticas qui-quadrado obtidas pelos 2 modelos e se essa diferença ultrapassar 3,84 (qui-quadrado crítico a 1 grau de liberdade) constata-se que os construtos são diferentes, ou seja, medem objetos realmente diferentes. De acordo com os resultados obtidos (Tabela 4), a diferença entre Qui-Quadrados para o par de construtos analisado foi superior a 3,84, demonstrando a validade discriminante destes. 
Tabela 4. Qui-Quadrado do modelo

\begin{tabular}{|c|c|c|c|}
\hline & \multicolumn{2}{|c|}{ Qui-Quadrado do Modelo } & \multirow{2}{*}{$\begin{array}{l}\text { Diferença dos Qui- } \\
\text {-Quadrados }\end{array}$} \\
\hline & Covariância $=1$ & Covariância Livre & \\
\hline SGH vs. SFOH & 119,464 & 86,669 & 32,795 \\
\hline
\end{tabular}

\section{CONCLUSÕES}

O inquérito para o presente artigo foi realizado numa época alta de procura dos hostels na cidade do Porto, em Portugal, mas a procura por este tipo de alojamento tem vindo a aumentar. Os resultados do inquérito comprovam que de facto, se trata de um tipo de hospedagem low cost. Os hóspedes apresentam uma idade média relativamente baixa (27 anos), $76,9 \%$ são solteiros e mais de $50 \%$ apresentam um rendimento anual inferior a $20.000,00 €$. As estadias por parte dos hóspedes são curtas (cerca de 70,6\% fica até 3 noites) e grande parte fica no hostel integrado num grupo de amigos. Mais de metade tem como objetivo principal o turismo e conhecer uma nova cidade e a maioria faz a marcação usando o site sobre hostels (booking). Este tipo de hóspedes valoriza o facto deste alojamento permitir organizar viagens de forma independente e flexível e permitir atividades mais informais, também pelo facto de ser um alojamento barato e ter cozinha disponível. Estas conclusões apresentadas estão de acordo com o exposto na revisão da literatura, nomeadamente referidas nos estudos de Valls (2016), Brochado e Gameiro (2013) e Martins, Rachão e Costa (2018).

Relativamente ao conforto o que mais valorizam é a limpeza, nomeadamente da zona de banhos, das áreas comuns e da cozinha, o que está em concordância com os estudos de Santos (2016) e Rashid-Radha (2015). Estes hóspedes procuram hostels com boa aparência e com uma paisagem envolvente agradável. Os hóspedes valorizam a localização numa zona segura, com facilidade de transportes públicos e na zona mais antiga (histórica) da cidade. Num hostel o design e o ambiente são aspetos importantes. O ambiente deve ser acolhedor, confortável, calmo e tranquilo, como referido por Brochado e Gameiro (2013) e Bahls (2015).

Foi efetuada uma análise fatorial confirmatória às preferências dos hóspedes dos hostels na cidade do Porto e concluiu-se que havia oito fatores determinantes na escolha de um hostel. Os itens que diferenciam os oito fatores foram confirmados pelas escalas apresentadas. O primeiro fator é a segurança geral do hostel, onde os itens revelam a importância dada e a preocupação dos hóspedes com os aspetos da segurança. Num ambiente informal, onde as pessoas mal se conhecem, é uma preocupação e um aspeto valorizado, nomeadamente se as portas tem segurança, se há vigilância da polícia nas redondezas, a existência de funcionário na portaria (ente outros). O segundo fator é a limpeza do hostel, particularmente na zona de banhos, dos quartos, dos dormitórios, da cozinha e das áreas comuns. O terceiro fator é o mobiliário básico do hostel. Trata-se do mobiliário de uso comum como o fogão, o micro ondas, o multibanco e o wi-fi. O quarto fator são os serviços de apoio aos hóspedes. Trata-se dos serviços complementares como o aluguer de material de apoio, informações e ligações a centrais de táxi. $O$ quinto fator é o design e o ambiente. $O$ design interior e exterior, o possuir instalações e equipamentos modernos e um ambiente acolhedor e confortável é algo que é bastante valorizado pelos hóspedes. $O$ sexto fator são as externalidades positivas 
de localização e revelam o desejo de proximidade do hostel ao rio, à praia e a jardins cuidados. O sétimo fator é o comércio e o entretenimento dos hóspedes. Podemos concluir que os hóspedes procuram conhecer e conviver com novos viajantes e procuram experiências únicas de viagem. Por último, um outro fator relacionado com a segurança mais objetiva, como a existência de cofre individual, a segurança da área de localização e a segurança do próprio hostel. $O$ instrumento final de medida ficou com 38 questões, o que diminui em muito o questionário apresentado aos hóspedes em função da revisão da literatura. Os fatores resultantes da análise fatorial confirmatória apresentados neste trabalho, apresentam fatores, até agora não referenciados nos estudos anteriores, nomeadamente o design e o ambiente do hotel, o que vai de encontro ao estudo de Kim \& Perdue (2013) que referia que os hóspedes não consideram apenas os atributos cognitivos, mas também os afetivos e sensoriais, promovidos pelos gestores hoteleiros como forma de fazer progredir os seus negócios.

\section{REFERÊNCIAS}

Abrantes, J. M. (2014) Hostels e centros históricos das cidades: Envelhecimento ou rejuvenescimento?. Tourism and Hospitality International Journal, 3(4), 355-383.

Bahls, Á. \& Pereira, R. (2017) Hostel, uma casa sem paredes: em busca de uma matriz classificatória de áreas físicas. Applied Tourism, 2(2), 01-23.

Bahls, A. (2015) Hostel: proposta conceitual, análise socioespacial e do panorama atual em Florianópolis (SC) Dissertação de Mestrado, Turismo e Hotelaria, Universidade do Vale do Itajaí (UNIVALI): Balneário Camboriú, Brasil.

Brochado, A. \& Gameiro, C. (2013) Toward a better understanding of backpackers' motivations. Tekhne, 11(2), 92-99. https://doi.org/10.1016/j.tekhne.2013.11.001

Brown, T. (2006) Confirmatory factor analysis for applied research. The Guilford Press. New York: The Guilford Press. https://doi.org/10.1198/tas.2008.s98

Cró, S. \& Martins, A. (2018) Hotel and hostel location in Lisbon: looking for their determinants. Tourism Geographies, 20(3) 504-523. https://doi.org/10.1080/14616688.2017.13603 $\underline{86}$

Cró, S., Martins, A. M., Simões, J. M. \& Calisto, M. D. L.(2018) (2018) Effect of Security on Hostels' Price Premiums: A Hedonic Pricing Approach. Cornell Hospitality Quarterly, https://doi.org/10.1177/1938965518777224.

Fitzpatrick, S. \& Wygnanska, J. (2007) Harmonising hostel standards: comparing the UK and Poland. European Journal of Homelessness, 1, 41-66. Recuperado de: https://www. feantsaresearch.org/download/ejh_vol1_article23490544034146070254.pdf

Fornell, C. \& Larcker, D. F. (1981) Evaluating structural equation models with unobservable variables and measurement error. Journal of Marketing Research, 18(1), 39-50. https:// doi.org/10.2307/3151312

Hair JR., J., Black, W., Babin, B. \& Anderson, R. E. (2010) Multivariate Data Analysis. (7th ed.) Upper Saddle River: Prentice Hall.

Hecht, J. A. \& Martin, D. (2006) Backpacking and hostel-picking: an analysis from Canada. International Journal of Contemporary Hospitality Management, 18(1) 69-77. DOI: 10.1108/09596110610641993 
Hory, G., Major, Z., Müllner, P. \& Benko, M. (2017) Exploration of spatial design issues at backpacker hostels in Budapest' s historic center: Informality, density, and adaptability. Frontiers of Architectural Research, 6(2), 157-168. https://doi.org/10.1016/j. foar.2017.02.005

Hu, L. \& Bentler, P. M. (1999) Cutoff criteria for fit indexes in covariance structure analysis: Conventional criteria versus new alternatives. Structural Equation Modeling: $A$ Multidisciplinary Journal, 6(1), 1-55, https://doi.org/10.1080/10705519909540118

Kim, D., \& Perdue, R. R. (2013) The effects of cognitive, affective, and sensory attributes on hotel choice. International Journal of Hospitality Management, 35, 246-257. https:// doi.org/10.1016/i.ijhm.2013.05.012

Marôco, J. (2010) Análise de Equações Estruturais: Fundamentos teóricos, Software \& Aplicações. Pêro Pinheiro: ReportNumber.

Martins, M., Rachão, S. \& Costa, R. (2018) Electronic word of mouth: Does it really matter to backpackers? Booking website reviews as an indicator for hostels' quality services. Journal of Quality Assurance in Hospitality \& Tourism, 1-27, https://doi.org/10.1080/1 $\underline{528008 X .2018 .1429980}$

Mikulić, J., Krešić, D., Miličević, K., Šerić, M. \& Ćurković, B. (2016) Destination attractiveness drivers among urban hostel tourists: An analysis of frustrators and delighters. International Journal of Tourism Research, 18(1), 74-81. https://doi.org/10.1002/ itr.2034

Moreira, A. C., Tavares, F. O. \& Pereira, E. T. (2014) The Portuguese Residential Real Estate Market. An Evaluation of the Last Decade. Panoeconomicus, 61(6), 739-757, doi:10.2298/PAN1406739T, 2014.

Musa, G. \& Thirumoorthi, T. (2011) Red Palm: exploring service quality and servicescape of the best backpacker hostel in Asia. Current Issues in Tourism, 14(2), 103-120. https://doi. org/10.1080/13683500903511125

Santos, G. (2016) Worldwide hedonic prices of subjective characteristics of hostels. Tourism Management, 52, 451-454. https://doi.org/10.1016/j.tourman.2015.07.001

Silva, M. (2014) O segmento low cost na indústria hoteleira em Coimbra: o caso dos hostels. Relatório de Estágio, 2ํ Ciclo em História de Arte, Património e Turismo Cultural, Universidade de Coimbra, 2014. https://estudogeral.uc.pt/handle/10316/27600

Tavares, F. O., Pereira, E. \& Moreira, A. (2012) Avaliação Imobiliária: Dois Casos da Importância das Vistas como Externalidades. Revista de Gestão dos Países de Língua Portuguesa, 11(4), 02-13. http://bibliotecadigital.fgv.br/ojs/index.php/rbpg/article/view/78725

Tavares, F., Pacheco, L. \& Borges, J. (2016) Fatores indiciadores do preço de um quarto de hotel: uma aplicação a uma amostra de hotéis portugueses. Revista Espacios, 37(26), 1-11, ISSN 0798 1015. http://www.revistaespacios.com/a17v38n61/17386118.html

Tavares, F.\& Fraiz Brea, J. (2017) Determinantes de preferência nos Hostels: Uma revisão da literatura. Revista Espacios, 38(61), 1-12, ISSN 0798 1015. http://www.revistaespacios. com/a17v38n61/17386118.html

Timothy, D., \& Teye, V. (2009) Tourism and the lodging sector. Oxford: Butterworth-Heinemann. Valls, J. F. (2016) Impacto del low cost en los precios hoteleros españoles. Papers de Turisme, (35), 81-88. http://www.papersdeturisme.gva.es/ojs/index.php/Papers/article/ viewFile/462/389 
Veríssimo, M. \& Costa, C. (2018) Do hostels play a role in pleasing Millennial travellers? The Portuguese case. Journal of Tourism Futures, 4(1), 57-68. https://doi.org/10.1108/ JTF-12-2017-0054

Volante, P. (2011) O segmento low-cost da indústria hoteleira em Portugal: o caso dos hostels. Projeto de Mestrado em Gestão. ISCTE- Business School, Instituto Universitário de Lisboa. https://repositorio.iscte-iul.pt/handle/10071/4068

Wahlberg, T. \& Ramalho, N.; Brochado, A. (2017) Quality of working life and engagement in hostels. Tourism Review, 72(4) 411-428. https://doi.org/10.1108/TR-03-2017-0050

Wilson, E., Ateljevic, I., Hannam, K. \& Atelievic, I. (2008) Challenging the'tourist-other'dualism: gender, backpackers and the embodiment of tourism research. Backpacker tourism: Concepts and profiles, 95-110. https://www.cabdirect.org/cabdirect/ abstract/20083026245 